\title{
VERDAD, DELIBERACIÓN Y LEY NATURAL EN LA FORMA DEL DERECHO DE FERNANDO ATRIA
}

\author{
TRUTH, DELIBERATION, AND NATURAL LAW ON FERNANDO \\ ATRIA'S LA FORMA DEL DERECHO
}

\section{Eduardo Fuentes Caro*}

\begin{abstract}
RESUMEN: ¿¿Hay algo inapropiado en referir a la verdad en la deliberación política democrática? En este artículo queremos analizar la propuesta de Fernando Atria al respecto. Sotiene que la verdad moral se disuelve en la política. En pocas palabras, eso quiere decir que la verdad moral existe pero solo se presenta como el resultado de la deliberación política. Luego, concluye que la ley natural se reduce a la política democrática. Por ende, no se la puede emplear "dogmáticamente". Argumentaremos que la posición atriana adolece del defecto de no prestar atención al papel de las creencias que vuelven inteligibles los contextos deliberativos. En consecuencia, defendemos la legitimidad en principio del uso "dogmático" de la verdad en la deliberación política, y específicamente de la ley natural.
\end{abstract}

Palabras clave: verdad, democracia, deliberación política, ley natural, Fernando Atria.

ABSTRACT: Is it inappropriate to appeal to truth within democratic political deliberation? In this article we will analyze Fernando Atria's proposal. Atria's thesis is provocative: moral truth dissolves into politics. Briefly, it means that while there is moral truth, it only shows itself as the result of political deliberation. Then, he concludes that natural law reduces to democratic politics. Thus, it cannot be used "dogmatically". We will argue that Atria's position suffers from not paying attention to the role of those beliefs that render deliberative contexts intelligible. Therefore, pace Atria, we defend the in principle legitimacy of the "dogmatic" use of truth in political deliberation, and particularly in regards to natural law.

Keywords: truth, democracy, political deliberation, natural law, Fernando Atria.

\section{INTRODUCCIÓN}

¿Cuál es la relación entre la verdad y la política? Más específicamente, ¿hay algo inapropiado en referir a la verdad en la deliberación política democrática? Hay una larga tradición en teoría política que ve una tensión entre democracia y verdad ${ }^{1}$. El motivo de la tensión no es difícil de ver. Una vez que una proposición ha sido identificada como verdadera ya no tiene sentido seguir deliberándola, y por lo tanto las posiciones contrarias quedan marcadas como equivocadas. La democracia, por otra parte, requiere que nos relacionemos entre nosotros como iguales, lo que implicaría tomar en consideración los juicios de todos.

\footnotetext{
* Doctor en Filosofía por la Universidad de los Andes. Actualmente es miembro del Departamento de Filosofía, Facultad de Ciencias Religiosas y Filosofía, Universidad Católica de Temuco. Código Orcid 0000-00032361-3750. Dirección postal:Casilla 15 D, Temuco, Chile. Dirección electrónica: eduardo.fuentes@uct.cl.

1 Véase Arendt (1961), Rorty (1983), Rawls (2005).
} 
No habría problema si todos estuviéramos de acuerdo acerca de qué juicios son verdaderos, pero eso equivaldría a un mundo donde no habría necesidad de política.

En este artículo queremos analizar la propuesta de Fernando Atria al respecto. Ella pretende ser un avance en nuestra comprensión del papel de la verdad en la deliberación política, ofreciendo una vía media entre el escepticismo y el dogmatismo. La tesis de Atria es provocadora: la verdad moral se disuelve en la política. En pocas palabras, eso quiere decir que la verdad moral existe pero solo se presenta como el resultado de la deliberación política. Fuera de ella carece de sentido, políticamente hablando. Todavía más, fuera de ella equivale a una falta del respeto que nos debemos como ciudadanos. Atria enmarca su tesis dentro de una teoría general del derecho, empleándola para -entre otras cosas- explicar en qué consiste la ley natural. Nosotros nos enfocaremos en la solidez de la tesis principal, pero indicaremos cómo de nuestra crítica se siguen serios problemas para su teoría sobre la ley natural.

La estructura del artículo es la siguiente. Primero, presentamos la tesis de Atria, reconstruyéndola en la versión que nos parece más fuerte. Segundo, analizamos el modo en que su teoría de la ley natural busca resolver el problema de las decisiones injustas, al introducir el sentido "anticipatorio" de la deliberación política. Tercero, argumentamos que la posición atriana adolece del defecto de no prestar atención al papel de las creencias que vuelven inteligible los contextos deliberativos. En consecuencia, contra Atria, defendemos la legitimidad en principio del uso "dogmático" de la verdad en la deliberación política. Cuarto, introducimos un concepto alternativo de respeto político que permite una deliberación respetuosa a pesar de la inevitabilidad del uso "dogmático" de la verdad; finalmente, mostramos cómo dicho uso afecta el lugar de la ley natural en la deliberación política.

\section{LA TESIS DE ATRIA}

Para Atria, los enemigos de la verdad en la política son de dos tipos. Por un lado están los escépticos, que niegan la existencia de la verdad; por el otro, los dogmáticos, que la afirman para negar el derecho de otros a sostener opiniones contrarias. Lo común a ambos grupos es que afirman la independencia de la verdad y la política. Los primeros nos dicen que son independientes porque en política no tiene sentido afirmar que algo es verdadero: la política se trata de negociación de intereses particulares. El emotivista, que cree que los juicios morales son solo expresiones de emociones sin contenido cognitivo, es un ejemplo paradigmático para Atria ${ }^{2}$. Uno de los correlatos institucionales del escepticismo son las teorías puramente agregativas de la democracia, puesto que tratan los votos como preferencia inanalizables ${ }^{3}$. Si no hay una verdad a la que se pueda llegar la deliberación deviene irrelevante, y en el peor de los casos perjudicial. En el plano jurídico, el correlato es el neo-constitucionalismo, que implica que "las cuestiones más importantes de la vida en

\footnotetext{
2 Véase MacIntyre (1987).

3 Véase DaHL (1989).
} 
común deben ser solucionadas no por deliberación pública sino por negociación sujeta al control de un juez"4.

Los segundos aceptan la existencia de la verdad, pero creen que "la verdad es algo que se presenta, por así decirlo, inmediatamente a la razón" ${ }^{5}$ y por lo tanto solo pueden entender el desacuerdo patológicamente. Dado que usan la verdad como premisa, no verían razón para deliberar con quienes están en el error. Ambas posiciones negarían la posibilidad de "producir formas de comunidad basadas en el reconocimiento recíproco" ${ }^{6}$, dejando espacio solo para la acción estratégica.

El error común a escépticos y dogmáticos es no entender la diferencia entre el uso apelativo y el uso constitutivo de la verdad. Funciona apelativamente "cuando la referencia a ella pretende reemplazar la necesidad del argumento"; funciona constitutivamente "cuando la referencia a ella opera no dentro de la práctica argumentativa sino como uno de sus supuestos" ${ }^{8}$. Si $\mathrm{H}$ le dice a $\mathrm{O}$ "debemos hacer $x$ porque $x$ es la respuesta verdadera", $\mathrm{H}$ está usando la verdad en el primer sentido: la emplea como una premisa en la argumentación. La verdad funciona constitutivamente cuando $\mathrm{H}$ refiere a ella para señalar que la práctica misma de la argumentación con $\mathrm{O}$ supone que hay una verdad a encontrar.

Atria sostiene que en política la verdad solo puede emplearse constitutivamente. La razón es que, como Hobbes notó, porque "la verdad nunca aparece en política in propiam persona, ella misma es (políticamente) irrelevante" . Cuando alguien afirma que "los impuestos son trabajo forzado" 10 o que "el socialismo es moralmente superior al capitalismo"11 es irrelevante la convicción con la que crea ambas proposiciones: para un tercero siempre aparecen como sus creencias. La "gramática" de las creencias lo dictamina. Atria argumenta que creer que $p$ es equivalente a creer que es verdadero que $p$, por lo que afirmar "creo que $p$ pero no es verdad que $p$ " carecería de sentido. La creencia es transparente a la verdad: la expresión "y es verdad que $p$ " no agregaría nada a "creo que $p$ "12. Pero, entonces, cuando alguien afirma que sus creencias son verdaderas no nos está dando más información que la que nos dió cuando nos las hizo conocidas. El punto político relevante es que cuando $\mathrm{H}$ pide a $\mathrm{O}$ que se someta a lo que $\mathrm{H}$ afirma como verdadero está, desde el punto de vista de $\mathrm{O}$, pidiendo que se someta a las creencias de H. Frente a "es verdad que $p$ " el oyente puede siempre reemplazar "es su creencia que $p$ ". Para $\mathrm{O}$ ambas expresiones son intercambiables, aunque no lo sean desde el punto de vista de $\mathrm{H}^{13}$.

Más adelante examinaremos por qué debe usarse constitutivamente; por el momento reconstruiremos su razonamiento contra el uso apelativo. Fundamentalmente, el uso

\footnotetext{
4 Atria (2016) p. 391.

5 Atria (2016) p. 368

6 Atria (2016) p. 369

7 Atria (2016) p. 364.

8 Atria (2016) p. 364.

9 Atria (2016) p. 362.

10 Véase Nozick (1974).

11 Véase Cohen (2009).

12 En este punto Atria refiere a FINNIS (1983).

13 La misma idea se encuentra en NAGEL (1987).
} 
apelativo de la verdad atenta contra nuestra igual dignidad. Dado que las creencias son transparentes a la verdad, defender una ley coercitiva solo apelando a su verdad equivale a defender que los otros deben someterse a nuestras creencias, luego, que ellos vivan en conformidad a nuestra voluntad y no la suya. Claro, a nosotros "la ley es justa" se nos presenta como una verdad, y por lo tanto no creemos estar imponiendo nuestra voluntad. Empero, como acertadamente señala Nagel ${ }^{14}$, desde el punto de vista de los otros nuestra acción así sería descrita. Nótese que afirmar que nuestra descripción debe ser preferida solo reitera el problema un nivel más arriba.

Ahora bien, ¿por qué someterse a una ley que se le aparece solo como la creencia de $\mathrm{H}$ atentaría contra la dignidad de $\mathrm{O}$ ? En otras palabras, ¿qué hay de malo en someterse a la opinión de otros? La respuesta de Atria lo asemeja, a pesar de que él no lo explicita, con la tradición del liberalismo justificatorio ${ }^{15}$. Afirma que "[l]o que define a lo político es el reconocimiento del otro como igual" 16 ; de lo que concluye que "no basta que yo esté convencido de la verdad de $x$ para que pueda exigir al otro que viva conforme a $x$ : le debo (a él) hacer transparente (para él) el hecho de que $x$ es bueno, de modo que para él vivir conforme a $x$ no sea vivir conforme a mi voluntad sino vivir conforme a lo que realiza su propia naturaleza, es decir, lo que él realmente quiere" ${ }^{17}$.

Suponiendo, como parece plausible, que Atria piensa que la legitimidad (el derecho de la autoridad política para mandar, incluso mediante coerción) se funda en el (o al menos depende del) respeto a la igual dignidad, se sigue que él podría formular el siguiente criterio de legitimidad: el uso del poder político es legítimo solo si su justificación no emplea la verdad apelativamente. En otras palabras, solo si se le justifica a cada persona mediante razones que ella podría aceptar ${ }^{18}$.

A primera vista el argumento parece razonable. ¿Cómo se podría respetar nuestra igual dignidad si nuestras justificaciones del poder político no son aceptables para todos? ¿Acaso no sería experimentado como meramente privilegiar las creencias propias? Respetar la dignidad, dice Atria, consiste en que "cada uno reconoce que la confianza que tiene en su juicio a la hora de pesar las razones no tiene porqué ser aceptada por el otro"19. Así, no justificarle al otro nuestros juicios sería faltarle el respeto porque equivaldría, en los términos de Scanlon, a afirmar que "no tendría el mismo derecho a ser considerado en la definición de lo que es nuestra sociedad ni el mismo derecho a participar en la determinación de lo que esta será en el futuro" ${ }^{20}$. Siguiendo a Thomas M. Besch llamemos a esta concepción

\footnotetext{
14 Nagel (1987) pp. 226 y ss.

15 Algunos ejemplos de este liberalismo justificatorio son Larmore (1987), RaWls (2005), SCANLON (1998), Gutmann y Thompson (1996), Forst (2011), Gaus (2011).

16 Atria (2016) p. 400.

17 Atria (2016) p. 400.

18 Compárese con el Principio de Legitimidad Liberal de John Rawls: "Nuestro ejercicio del poder político es totalmente propio solo cuando se ejercita de acuerdo a una constitución, de la que es razonable esperar que sus aspectos esenciales sean aceptados por todos los ciudadanos en cuanto libres e iguales, a la luz de principios e ideales aceptables a su razón humana común”. RaWls (2005) p. 137. Todas las traducciones son propias.

19 Atria (2016) p. 409.

20 SCANLON (1996) p. 226.
} 
"concepción discursiva del respeto". De acuerdo a ella, las personas tienen un estatuto discursivo fuerte: $\mathrm{O}$ lo tiene cuando los fundamentos en los que $\mathrm{H}$ está comprometido a actuar dependen de lo aceptables que sean para $\mathrm{O}^{21}$. Es decir, lo que sea discursivamente aceptable para $\mathrm{O}$ determina los modos en que $\mathrm{H}$ puede comprometerse a actuar. Una concepción no discursiva no entiende el respeto como una función de la aceptabilidad de las razones, por lo que no hacer "transparentes" las creencias en la deliberación no sería considerado por sí mismo una falta de respeto a la igual dignidad. La concepción discursiva pretende encarnar la idea de que respetar a alguien es reconocerlo como un igual miembro de la comunidad moral ${ }^{22}$.

El respeto discursivo es un modo plausible de darle contenido al respeto que nos debemos como iguales en la deliberación política. Evidentemente, no todas las relaciones personales han de estar sometidas a este estándar: no se trata de una concepción de respeto absoluta. El deber de justificar nuestras creencias se funda en la relación de igualdad en la que nos encontramos en cuanto ciudadanos y a la naturaleza coercitiva de las decisiones políticas. Por eso el argumento contra el uso apelativo de la verdad debe ser entendido como limitándose a la esfera política ${ }^{23}$. Adicionalmente, hay algo en la lógica misma de la política que pareciera implicar esta concepción de respeto. Al menos en la política democrática, cuando deliberamos lo que intentamos hacer es llegar a una conclusión a nombre de todos. Si queremos determinar si "la paridad de género es importante" es un juicio verdadero, queremos que la conclusión a la que lleguemos pueda ser considerada como nuestra.

Más adelante argumentaremos que no es posible deliberar sin usar apelativamente la verdad, por lo que hemos de rechazar la concepción discursiva del respeto. O aceptar que la deliberación política constituye irremediablemente una falta de respeto a nuestra igual dignidad. Mas antes resta examinar el argumento a favor del uso constitutivo de la verdad.

Supongamos que queremos establecer si es verdadero que el capitalismo es injusto. Con tal fin intercambiamos argumentos, para convencernos de lo que creemos que es correcto. No obstante, si $\mathrm{H}$ no cree que haya una verdad sobre ese asunto entonces no busca obtener el asentimiento racional de $\mathrm{O}$. Si la proposición en disputa carece de valor de verdad entonces es imposible que haya razones para aceptarla en cuanto verdadera. Si H cree eso su acto de argumentar es en realidad un simulacro, entonces no hay deliberación. Los argumentos devienen herramientas de manipulación. Mutatis mutandis para el caso de O. La deliberación presupone que aceptemos que hay una verdad a ser descubierta ${ }^{24}$.

Se sigue que el escéptico también niega el respeto al otro. Siguiendo a MacIntyre, Atria ve en esta postura la desaparición de la diferencia entre relaciones de reconocimiento y relaciones manipulativas. El escepticismo es la privatización final: al negar la verdad niega lo común a todos. Es el equivalente político del solipsismo.

\footnotetext{
21 BESCH (2014) p. 208.

22 Se trata en toda esta discusión del respeto de reconocimiento, y no de aprecio, en la famosa distinción de DARWALL (1977).

23 De manera importante, cabe señalar que Atria argumenta que hay espacios donde explícitamente no estamos sometidos a este deber, lo que redunda en que podamos coordinarnos de un modo no deliberativo. El mercado sería un ejemplo paradigmático de lo anterior. Véase Atria et al. (2013).

$24 \mathrm{O}$ "construida", si nos inclinamos por el constructivismo moral.
} 
Aunque no tenemos objeciones a la función constitutiva de la verdad sí vale la pena mencionar que Atria concluye demasiado de ella. Además del argumento normativo contra la función apelativa, examinado arriba, ofrece un argumento de tipo conceptual. Sostiene que "si las prácticas deliberativas están constituidas por la idea de verdad, o de objetividad, la idea de objetividad o de verdad solo tiene sentido al interior de nuestras prácticas deliberativas", de lo que infiere que "[l]a pregunta por la verdad o la objetividad, entonces, es una pregunta política" 25 . Esa inferencia es, empero, falaz. No se sigue de que las prácticas deliberativas estén constituidas por la idea de verdad que esta solo tenga sentido al interior de ellas. Constituir algo no implica ser constituido por eso: la constitución no es una propiedad simétrica. Atria tendría que haber mostrado que la idea de verdad que constituye dichas prácticas solo puede ser entendida como esencialmente interna a aquéllas. Esto es, debió haber mostrado la verdad del constructivismo moral.

Si bien en Atria (2016) no asume explícitamente dicha posición metaética, sí lo hace en Atria (2018) 26. A pesar de eso, es difícil reconciliar tal posición con la afirmación de que al deliberar debemos mostrarle al otro que "vivir conforme a $x$ no [es] vivir conforme a mi voluntad sino vivir conforme a lo que realiza su propia naturaleza" ${ }^{27}$. Pareciera que lo hace verdadero a una proposición moral $p$ es su conformidad con la propia naturaleza, y no el hecho de que sea acordado bajo ciertas circunstancias. Es debido a esto que es posible para Atria formular una teoría de la ley natural, esto es, una teoría acerca de lo que "es bueno para los seres humanos dada nuestra naturaleza" 28 . Nótese que esto no es trivial, porque la deliberación será distinta según lo que queramos mostrar. No es lo mismo defender $p$ en virtud de que no puede ser rechazada razonablemente y defender que $p$ es acorde a nuestra naturaleza.

Atria podría responder que el argumento anterior es injusto. Incluso si tiene sentido conceptual hablar de la verdad moral fuera de las prácticas deliberativas, no lo tiene prácticamente. Ella siempre se nos presenta dentro de esas prácticas: es así como la descubrimos. $\mathrm{Al}$ menos así se nos presenta en la esfera política. En nuestros hogares podemos creer lo que nos plazca, estando muy convencidos de la verdad de nuestros juicios morales. Pero en política, recordemos, la verdad nunca aparece en persona. No hay modo de identificar una proposición moral como verdadera sino es por medio de los procesos deliberativos (y la decisión mayoritaria, como se verá más adelante): cuando se hacen transparentes las razones por las que sería verdadera o no.

Ahí radica la crítica de Atria a las teorías epistémicas de la democracia. Se podría pensar que dada la importancia que otorga a la deliberación concluiría que el valor de la democracia radica, al menos en parte, en que "acierta" con la verdad moral ${ }^{29}$. Pero como tales teorías creen que lo moral puede conocerse fuera de lo político "devalúa[n] lo político, porque entonces la razón por la cual lo político es una fuente de normatividad es externa

\footnotetext{
25 ATria (2016) p. 377.

26 Atria (2018) p. 55.

27 Atria (2016) p. 400.

28 Atria (2016) p. 395.

29 "Lo que caracteriza a una justificación epistémica de la democracia es que entiende que el procedimiento democrático es el que da más garantías de corrección sustantiva de la decisión tomada" (379).
} 
a lo político: es consecuencia de la comparación entre diversos métodos para identificar lo que es moralmente correcto" 30 .

Dado que el argumento conceptual es defectuoso, hemos de interpretar la afirmación anterior según su contraparte normativa. La idea sería entonces que en la práctica política no se puede, so pena de trato irrespetuoso, identificar una proposición moral como verdadera sin recurrir al proceso deliberativo (y eventualmente de decisión mayoritaria). La verdad moral solo se muestra políticamente en los procesos de formación de la voluntad política. Por lo tanto, en la práctica no es posible afirmar que la democracia acierta más que otro sistema, ya que solo con ella obtenemos la verdad.

Nótese una consecuencia de este razonamiento. Si la verdad moral se presenta solo de tal modo, entonces pareciera que es imposible llegar a decisiones políticas inmorales. En otras palabras, puesto que el único criterio de la moralidad de una decisión es que sea la conclusión de la deliberación política se seguiría que nunca podríamos considerar inmoral una de esas conclusiones. Después de que una proposición ha pasado por todos los procedimientos de formación de voluntad política, convirtiéndose en ley, tendríamos que afirmar que es justa. Sería un giro irónico al adagio iusnaturalista lex iniusta non est lex: no hay leyes (que podamos afirmar que son) injustas.

Quien quiera interpretar el adagio a la manera tradicional tiene que sostener que puede captar la injusticia de la ley directamente, esto es, sin referir a los procesos democráticos que nos llevaron a concluir que la proposición que la ley expresa es justa. Mas ello equivale, en la esfera política, a atribuirse un acceso privilegiado a la verdad: a usarla apelativamente.

He aquí un problema. Al parecer estamos impedidos de criticar respetuosamente la conclusión de una deliberación política. La igual dignidad tendría como resultado una restricción epistémico-normativa: no hay evidencia aceptable para objetar la moralidad de dicha conclusión ${ }^{31}$. Mas todos estamos familiarizados con procesos deliberativos cuyas conclusiones son (a nuestro juicio) erróneas. ¿Cómo podemos reconciliar ambas cosas? La respuesta de Atria refiere a la naturaleza anticipatoria de nuestras formas institucionales, y entronca directamente con su teoría de la ley natural.

\section{ANTICIPACIÓN Y LEY NATURAL}

¿Cómo se puede criticar el resultado de una deliberación política sin usar apelativamente la verdad? Atria propone repensar el papel de los estándares de evaluación, puesto que la dificultad radica en atribuirse la posesión de estándar externo a la deliberación misma. Sugiere entender la relación entre la verdad moral y la política en términos de justicia puramente procesal imperfecta. Como es sabido, Rawls distinguió dos dimensiones en los procedimientos de justicia: la existencia de un estándar externo de justicia y la infalibilidad del procedimiento ${ }^{32}$. De las cuatro combinaciones posibles Rawls solo consideró

\footnotetext{
30 Atria (2016) p. 379; énfasis en el original.

31 Es normativo porque el criterio de aceptabilidad se funda en la concepción discursiva del respeto; es epistémico porque niega la existencia de evidencia que cumpla ese criterio.

32 Véase RAwls (1999), sec. 14.
} 
tres: procedimientos infalibles en acertar al estándar externo (justicia procesal perfecta), procedimientos falibles en acertar al estándar externo (justicia procesal imperfecta), y procedimientos infalibles en los que no hay un estándar externo (justicia puramente procesal). En estos últimos el resultado del procedimiento es por definición justo. Excluyó la cuarta combinación: procedimientos falibles en los que no hay un estándar externo (lo que Atria llama "justicia puramente procesal imperfecta”). Es fácil ver por qué la excluyó. Si no hay un estándar externo, ¿cómo puede el procedimiento fallar? ¿No es acaso, en ausencia de ese estándar, el procedimiento el único estándar?

Atria repara en que la justicia puramente procesal requiere ser realizada, ya que no hay estándar externo al proceso para establecer el resultado; la justicia procesal imperfecta, por el contrario, puede no ser realizada e incluso así establecerse la corrección del resultado. Basta con acceder al estándar externo por otros medios. La justicia puramente procesal imperfecta se asemeja a la primera porque también debe ser realizada, y a la segunda porque puede fallar. Aunque a veces falle en dar con el resultado correcto, no hay otro modo de acceder a él. Puesto que arriba hemos rechazado el argumento conceptual, es mejor interpretar a Atria como afirmando que no es posible acceder a aquél respetando nuestra igual dignidad. Esto es, en la práctica política no podemos hacer uso positivo del estándar externo sino solo negativamente: "provee de un criterio para identificar los déficits del procedimiento" ${ }^{33}$. No se puede apelar al estándar externo para identificar los casos que cumplen el estándar, por lo que no se usa apelativamente sino solo constitutivamente. Constituye al procedimiento en cuanto es su objetivo, permitiéndonos solamente decir cuándo hay progreso o retroceso pero sin comparar "dos procedimientos sub especie aeternitatis" 34 para determinar cuál es más fiable o no.

El lector está excusado de encontrar todo esto bastante oscuro. ¿Cómo sabemos que el procedimiento tiene déficits si no podemos comparar sus resultados con el estándar externo? Para aclarar la idea Atria recurre a la noción de la dimensión anticipatoria de las instituciones. En breve, los procedimientos institucionales pueden mostrar un estado de cosas de modo incompleto, señalando cómo serían las relaciones humanas si ese estado de cosas se completase. Así, el derecho de contratos anticipa un estado de cosas en el que hay reconocimiento pleno entre las personas, aunque en la práctica ese estado de cosas está incompleto: hay reconocimiento parcial. En algunas situaciones, no obstante, las condiciones actuales impiden que las instituciones anticipen el estado de cosas buscado, volviendo a la institución opresiva (puesto que el estado de cosas buscado es emancipador). Ello sucede en el derecho laboral, que restringe el rango de acuerdos que las partes pueden tomar porque reconoce que bajo condiciones capitalistas los trabajadores no gozan de autonomía efectiva.

La justicia puramente procedimental imperfecta consistiría entonces en un procedimiento que apunta hacia un estándar que no existe fuera del proceso mismo pero que tampoco se realiza completamente en él. Eso quiere decir que su imperfección no radica -a diferencia de la justicia procedimental imperfecta- en la probabilidad de no acertar, sino que siempre acierta parcialmente. En este sentido el estándar tiene una función negativa, ya

\footnotetext{
33 Atria (2016) p. 383.

34 Atria (2016) p. 383.
} 
que nunca podemos determinar su contenido positivamente y emplearlo como premisa en la deliberación. Aquello que se nos da en los procedimientos sería simplemente el estado de cosas parcial.

Entonces, podemos criticar a una ley resultante de procesos democráticos solo internamente: no logra aquello que le da sentido. Por ejemplo, podemos ver que las leyes de derechos civiles son insuficientes porque logran imperfectamente lo que se proponen, la igual libertad. En efecto, ese es el argumento de Atria para adoptar los derechos sociales; ellos son necesarios para brindar las condiciones materiales necesarias para ejercer la libertad ple$\mathrm{na}^{35}$. En este sentido el carácter anticipatorio de las instituciones también tiene una dimensión retrospectiva, ya que nos permite ver cómo el camino recorrido estaba ya impreso en el pasado. Dicho de otro modo, la verdad de la justicia se nos revela como una radicalización de lo que los procesos democráticos habían mostrado como la verdad de la justicia en ese momento. Atria, con sobrada razón, distingue esto de una teoría de la historia progresista donde el futuro es mejor que el pasado porque viene después, o donde el futuro ejerce una especie de influencia causal. Digamos, una dictadura no es mejor que la democracia que derrocó porque viene después ${ }^{36}$.

Lo anterior permite comprender la teoría atriana de la ley natural y con ella la crítica a las decisiones políticas. El núcleo de su teoría es que el contenido de la ley natural se identifica con el de las decisiones democráticas. Sostiene que todo defensor de la ley natural debe afirmar que ella es "en principio transparente a la razón de todos" ${ }^{37}$. Dado lo expuesto hasta ahora, ello significa que ella en principio puede mostrarse en los procedimientos democráticos. Recuérdese que Atria cree que en la deliberación democrática lo que hacemos es mostrarnos que $x$ es bueno para nosotros en tanto conforme a nuestra naturaleza. Es decir, en la deliberación queremos determinar si $x$ es parte de la ley natural o no. Mas como los procedimientos democráticos tienen una dimensión anticipatoria, nuestras conclusiones sobre el contenido de la ley natural también tendrán ese carácter. Hasta que no vivamos bajo una sociedad donde nuestra naturaleza se realice plenamente el contenido de la ley natural estará sujeto a modificación (es decir, radicalización). La contingencia de las conclusiones de la ley natural es una consecuencia sorprendente para una teoría iusnaturalista, pero se sigue claramente de su teoría general.

Repárese en que no es que las decisiones a las que llegamos luego de la deliberación hagan que cierta proposición sea parte de la ley natural. La tesis es que solo podemos respetuosamente afirmarla como parte suya si ella es el resultado de la deliberación; lo que la hace verdad es su conformidad con nuestra naturaleza. Por eso es una teoría iusnaturalista, aunque idiosincrática. Los iusnaturalistas "dogmáticos" creen que pueden conocer esa conformidad fuera de los procedimientos de formación de voluntad política, pero solo terminan faltándole el respeto a sus conciudadanos. Debido a la concepción discursiva de este, al afirmar que conocen esa conformidad así excluyen al resto de la comunidad política. Pero

\footnotetext{
35 Véase Atria (2018).

36 Véase Atria (2018) pp. 26-56.

37 Atria (2016) p. 395.
} 
entonces aquello que llaman "ley natural" no es la ley de toda la comunidad humana, pues algunos han sido excluidos. Luego, no puede ser ley natural ${ }^{38}$.

¿Qué pasa cuando los procedimientos democráticos, deliberación y eventualmente regla de la mayoría, sancionan conclusiones que creemos que son erróneas? ¿No podemos entonces criticar la injusticia? Podemos, pero no solo basándonos en la corrección o incorrección sustantiva de la decisión. Atria afirma que es "estrictamente ininteligible"39 preguntarse por la corrección sustantiva de una decisión atendiendo únicamente a su contenido e ignorando el procedimiento por el cual fue tomada. Dado que esa afirmación depende del fallido argumento conceptual, hay que modificarla diciendo que es estrictamente ininteligible preguntarse respetuosamente por su corrección sustantiva. Frente a una conclusión que consideramos incorrecta y no solo parcial la crítica debe referir al procedimiento por el que se arribó a ella.

Justamente eso es lo que Atria cree que una teoría de la ley natural debe preguntarse: ¿por qué hay procedimientos democráticos que llevan a conclusiones que no todos aceptamos como correctas? Puesto que la ley natural en principio es accesible para todos en la deliberación, la pregunta equivale a esta otra: ¿por qué en la deliberación no es transparente para todos lo que es bueno para nosotros según nuestra naturaleza? Téngase presente que el iusnaturalista no puede apelar a su conocimiento y decir simplemente que la gente es incompetente o malvada, ya que eso sería usar apelativamente la verdad. La respuesta se presenta inmediatamente: no vivimos en una completa democracia por lo que aquello que nos conviene no se hace patente en la deliberación. A diferencia de quienes creen que la ley natural funciona como un cortafuegos de la política, Atria cree que ella exige que vivamos vidas más políticas, para poder alcanzar pleno reconocimiento recíproco. El iusnaturalista debe señalar qué aspectos de nuestras vidas encierran un déficit de política, y por ende nos hacer tomar decisiones facciosas ${ }^{40}$. Para Atria, esto implica una crítica a nuestras formas de vida bajo el capitalismo contemporáneo. Cuando vivamos vidas plenamente políticas llegaremos al consenso. Por mientras, la regla de la mayoría es válida para nosotros ahora, mas anticipa la situación de reconocimiento pleno. Vivir en democracias imperfectas nos enseña progresivamente cómo vivir en una democracia perfecta ${ }^{41}$.

\section{CONTEXTOS DELIBERATIVOS}

En una primera aproximación, deliberar políticamente es intercambiar juicios sobre asuntos políticos. Los ciudadanos se tratan de convencer mutuamente de cierto curso de acción, que usualmente involucra al Estado. Ahora bien, toda deliberación tiene "condicio-

\footnotetext{
38 La justificación de esa inferencia yace en la afirmación atriana de que la ley natural ha de ser la ley no de esta o aquella comunidad política sino de toda la humanidad. Por ende, no puede excluir a nadie.

39 Atria (2016) p. 405.

40 "Por consiguiente, cuando hablamos de decisiones injustas hablamos de decisiones que institucionalmente cuentan como decisiones que van en el interés de todos, pero sustantivamente no lo hacen. Son decisiones facciosas". Atria (2016) p. 417.

41 Este es el sentido de la pedagogía lenta que Atria vincula con la instauración de los derechos sociales. Veáse Atria (2014).
} 
nes materiales". Esto es, ocurre en determinado lugar, con determinadas personas, con determinados canales de información, etcétera. En otras palabras, la deliberación política tiene un contexto. No es lo mismo deliberar en nuestras sociedades de masas que en el ágora. La naturaleza contextual de la deliberación tiene, defenderemos, importantes consecuencias epistémicas y políticas.

Recordemos que el argumento contra el uso apelativo parte constando un supuesto hecho: en la esfera política nuestras creencias siempre aparecen como creencias. Sin embargo, eso no puede ser así con todas nuestras creencias. De serlo la deliberación ocurriría en un vacío. Hay ciertas creencias que tenemos que considerar como verdaderas si es que vamos a empezar a deliberar en conjunto. Si $\mathrm{H}$ le afirma que $p$ a $\mathrm{O}$ y $p$ está dentro de esas creencias, entonces a $\mathrm{O} p$ se le aparece como la verdad y no simplemente como la creencia de $\mathrm{H}$.

Considérese esto. Aunque Atria defiende la disolución de la verdad moral en la política su argumento tiene que aplicar también a la verdad fáctica. Después de todo, en política los desacuerdos no son solamente por nuestras evaluaciones morales, sino también por los juicios fácticos. "El Estado es un administrador ineficiente" o "el cambio climático es causado por los humanos" son juicios fácticos, a pesar de tener obvias implicaciones normativas. No hay ninguna razón por la que tendríamos que hacer una distinción entre verdades fácticas y morales: ninguna de ellas se presentaría en persona. El posible constructivismo moral de Atria no cambia la situación, porque el punto hobbesiano depende de la "gramática" de las creencias y no de su contenido particular. ¿¿Se puede deliberar sin asumir que algunas proposiciones fácticas son verdaderas?

Veamos. ¿Es siempre posible mantener el orden público sin transgredir los derechos humanos? Es una pregunta fáctica, puesto que no evalúa moralmente ni el orden público ni la violación de los DD.HH. Muchas personas contestarán negativamente, lo que es compatible con preferir el orden o el respeto a los DD.HH. Personas razonables pueden estar en desacuerdo al respecto. Sin embargo, hemos de reparar en el hecho de que una deliberación donde esa pregunta está abierta es muy distinta a una donde se asume alguna respuesta. En Chile actualmente, por ejemplo, ninguno de los sectores políticos duda públicamente que la respuesta sea afirmativa. El contexto de la deliberación está delimitado en parte por esa proposición. Ponerla en duda es, en ese contexto, salirse de la discusión.

Acá no se trata de que haya algo malo en dudar de alguna de estas creencias, sino que hacerlo nos cambia de contexto. Sucede que nosotros deliberamos ya inmersos en la situación. La deliberación emprende el vuelo a la caída del crepúsculo, parafraseando a Hegel. Los hechos políticos se nos imponen antes de la deliberación, contextualizándola. Ciertamente podemos ignorar el contexto en el que surge la pregunta que motiva la deliberación, pero al hacerlo estamos cambiando la pregunta. En el ejemplo anterior, si cuestionamos la compatibilidad entre orden público y derechos humanos nuestra deliberación ha de incorporar argumentos sobre cómo ponderar ambos bienes; los que serían inadmisibles si todos asumiéramos una respuesta afirmativa. Su inadmisibilidad no es moral sino práctica: nos saca demasiado de lo que ya estamos haciendo.

Para que quede claro: no estamos formulando un principio moral contra preguntas "de orden superior". Tampoco estamos defendiendo el estado actual de las cosas, impidiendo que se cuestionen los fundamentos de nuestras prácticas políticas. Todo eso puede ser 
muy necesario. El asunto es otro, a saber, que hemos de estar conscientes que al dejar de dar por supuestas ciertas proposiciones estamos abandonando nuestra práctica inicial.

Precisemos. Afirmamos que toda deliberación incluye proposiciones que se asumen como verdaderas en ese contexto, y que no pueden dudarse sin abandonarlo. Siguiendo la terminología de Wittgenstein, son creencias bisagras ${ }^{42}$. No podemos dudarlas porque "la pregunta que planteamos y nuestras dudas dependen del hecho de que ciertas proposiciones están exentas de duda" ${ }^{33}$. La pregunta por la compatibilidad de los derechos humanos y el orden público supone que existen derechos humanos, entre otras cosas. Se sigue, por lo tanto, que no se puede investigar todo en un solo movimiento. Cada pregunta que hago forzosamente debo presuponer estas creencias bisagra, con lo que las preguntas han de ser necesariamente locales. Aplicado a la deliberación, carece de sentido decir que vamos a deliberar desde una "hoja en blanco", como si pudiéramos cuestionarlo todo y ofrecer argumentos para todas las creencias que formarán parte de la deliberación ${ }^{44}$.

Basándose en lo anterior, Michael Williams acuña el concepto de necesidades metodológicas. Ellas son "presuposiciones en vigencia tal que cuestionarlas lo llevaría a uno a cuestionar la competencia de la forma de investigación que ellas permiten” ${ }^{45}$. Para Williams, estas necesidades metodológicas dependen del tipo de investigación que se lleve a cabo. Nosotros podemos aplicar esta idea a la deliberación, tomando cada deliberación particular como una forma de investigación distinta. Habría necesidades metodológicas de la deliberación en abstracto, pero también de cada especie particular. Atria parece asumir que las deliberaciones se dan de modo abstracto. En el lenguaje actual, asume necesidades metodológicas generales, sin reparar en que las deliberaciones reales tienen particularidades ineludibles.

Lo último es crucial. Atria podría concedernos que hay ciertas creencias bisagras pero afirmar que son muy generales. Ellas se nos presentarían como la verdad en persona, pero solo ellas. Serían del tipo "el mundo existe", "las personas pueden ser convencidas mediante argumentos racionales", "la verdad puede ser encontrada mediante este proceso deliberativo". Ellas pondrían el marco sin resolver ninguna de las cuestiones en disputa, siendo comunes a cualquier deliberación. Por ende, el punto hobbesiano se mantendría en lo que es materia de la deliberación particular.

Supóngase que estamos deliberando acerca de la conveniencia de determinada ley y alguien cuestiona nuestra afirmación "las personas podemos controlar nuestros actos". ¿Qué

42 WitTGENSTEIN (1969).

43 Wittgenstein (1969) \$341.

44 Wittgenstein sostiene que tales creencias escapan a la evaluación epistémica: son “algo animal” (\$359). PRITCHARD (2018) infiere que por ende ellas no son para nada opcionales. Su no opcionalidad es una de las principales objeciones que tiene contra el contextualismo inferencial de Michael Williams, que será defendido por nosotros acá. Contra Pritchard, no se sigue de que una creencia bisagra sea sostenida con "certeza animal" el que no sea opcional. Cierto, no es opcional dentro del contexto de investigación, pero es opcional en el sentido de que podemos cambiar dicho contexto. El asunto, también discutido por Pritchard, es si es posible cambiar de contextos de investigación que no supongan algunos súper compromisos bisagras. Sea como sea, creemos que la posición de Williams (y con ella la nuestra) no requiere negar la existencia de esos súper compromisos; le basta con que ellos no agoten el universo de creencias bisagras.

45 Williams (2007) p. 102. 
tendríamos que responder? Según Atria, se nos pasa la carga de la prueba: tenemos que ofrecer razones (aceptables para quien cuestiona) en favor de esa afirmación. Mas eso es implausible, ya que lo corresponde es preguntar de vuelta a qué se refiere con la duda. Después de todo, cuando alguien cuestiona algo evidente lo apropiado es verificar si la persona entiende lo que está cuestionando o si quiere decir algo distinto. En palabras de Wittgenstein, "[h] ay casos en los que, si alguien da signos de duda sobre lo que nosotros no dudamos, no podemos con confianza entender sus signos como signos de duda" ${ }^{46}$. La posición atriana, y con ella cualquiera que niegue que cada deliberación tiene sus propias necesidades metodológicas, asume que la inteligibilidad de los cuestionamientos está dada. Es decir, que fuera de preguntas generales todo cuestionamiento es inteligible en cualquier contexto. Pero esa no es nuestra experiencia al deliberar. Si estamos en una convención constituyente y se cuestiona la afirmación "los constituyentes pueden confeccionar una nueva constitución” sería absurdo ofrecer razones para justificarla. En ese contexto nos sería difícil siquiera entender el cuestionamiento. Tómese otro ejemplo. Supóngase que alguien cuestiona la afirmación "las personas tienen derechos". A diferencia del anterior caso, acá no se trata de no entender las funciones de una convención constituyente, sino del contexto en que tiene sentido la deliberación. ¿Cómo podríamos participar en el proceso constituyente sin asumir que las personas tienen derechos? Nuestra participación es inteligible en parte debido a que asumimos la verdad de esa proposición, por lo que cuestionarla es ininteligible en ese contexto ${ }^{47}$.

La cualificación es crucial. La inteligibilidad de los cuestionamientos depende del contexto. Sin duda, en términos absolutos podemos entender ambas preguntas. Lo que pasa es que si tratamos de responderlas seriamente estaremos haciendo filosofía, no participando de una convención constituyente. Ahí radica la ininteligibilidad: no podemos entenderlas como preguntas reales al mismo tiempo que realizamos nuestra práctica. Una vez que nos percatamos de ello es claro que cada deliberación particular tiene sus necesidades metodológicas. Las deliberaciones comienzan intempestivamente, cuando ya estamos involucrados en prácticas determinadas.

Por "inteligibilidad" incluyo también factores más claramente pragmáticos. Así, a veces responder un cuestionamiento es demasiado $\operatorname{costoso}^{48}$. Volviendo al ejemplo de la convención constituyente, los plazos que tiene para deliberar vuelven ininteligibles algunas objeciones, porque responderlas costaría demasiado tiempo. En abstracto los constituyentes pueden entender que alguien cuestione el estándar de evidencia que se aplica en la convención, pero en concreto les puede parecer carente de toda plausibilidad porque demanda tiempo que no tienen. Los constituyentes asumen más o menos explícitamente que la evidencia debe poder ser recogida y procesada en el plazo asignado a la convención. Frente a la demanda por mayor evidencia pueden contestar que no entienden cómo obtenerla dados los plazos acordados. Si el objetor mantiene la pregunta ellos pueden responder que alguien no está entendiendo la situación en la que están. Nótese que lo que hay que entender es la "materialidad" de la deliberación, no solo sus características formales generales.

\footnotetext{
46 WitTGenstein (1969) $\$ 154$.

47 Véase Williams (2007) p. 102.

48 Véase Williams (2007) p. 104.
} 
Como dijimos, no estamos censurando moralmente los cuestionamientos a las creencias bisagras. Muchas veces debemos cuestionarlas, mas sabiendo que al hacerlo estamos cuestionando el contexto deliberativo mismo. Pedir más u otro tipo de evidencia en una asamblea puede ser equivalente a cuestionarla epistémicamente por completo ${ }^{49}$. Lo importante es reconocer que la idea de una deliberación pura, donde todo se puede cuestionar y toda afirmación debe ser defendida, es una ilusión.

Volviendo a Atria, nuestra conclusión es que el punto hobbesiano es falso. Hay ciertas creencias que se presentan en la deliberación - política o no- como la verdad, tanto generales como particulares. Atria cree que ello comporta una falta de respeto, pero sin que existan estas necesidades metodológicas la deliberación no puede siquiera comenzar. En sus términos, es imposible no emplear apelativamente la verdad. Ignorar ese hecho conlleva una aceptación acrítica de los contextos deliberativos particulares. En la última sección mostraremos por qué este resultado no implica que toda deliberación, y con ella la actividad política, es irrespetuosa; la conclusión que extraeremos es que es hay que abandonar la noción de respeto discursivo, reemplazándola con lo que llamamos "respeto institucional".

Antes de abandonar esta sección detengámonos en la aceptación acrítica de los contextos deliberativos. Dado que la política no es filosofía, en nuestras discusiones políticas no acostumbramos explicitar la naturaleza de la discusión. Ello invisibiliza el hecho de que hay creencias que se impondrán por la configuración misma del contexto deliberativo. Esto va más allá de una mera constatación sicológica. Hay creencias que están justificadas en un contexto y en otro no, por lo que tratar de optimizar racionalmente un contexto no impide que algunas posiciones ganen "por secretaría". La evaluación de la racionalidad de las creencias se realiza siempre dentro de un marco epistémico, por lo que cambios en este implican cambios en la evaluación. Siguiendo a Laura Callahan, podemos llamar a esta tesis permisivimo subjetivista básico ${ }^{50}$. Esta es bastante plausible, como muestran nuestras prácticas cotidianas: cuando nos cuentan que alguien creyó algo o hizo algo usualmente pedimos información sobre el contexto para saber si la persona estaba justificada. Luego, el que una creencia se presente como la verdad en un contexto y no en otro no significa que en alguno se haya producido un error. Dos deliberaciones pueden ser contextos igualmente aceptables en términos racionales aunque den lugar a distintas inferencias, dadas las diversas necesidades metodológicas. También es posible que uno de los contextos deliberativos sea deficiente, tanto en términos racionales como en términos prácticos. Es esta segunda deficiencia a la que hemos de estar más atentos. De lo aquí expuesto se sigue que es imposible contar con una deliberación que no privilegie algunas conclusiones sobre otras, por lo que solo podemos examinar cada contexto deliberativo para tener presente cuáles son privilegiadas y si nos es aceptable ello. Ciertamente, en muchas ocasiones solo podremos hacerlo una vez inmersos en la deliberación.

Volvamos al uso apelativo. No es necesario que alguien diga "debes creer que $p$ porque yo lo digo", como sugiere la imagen de Atria. Las necesidades metodológicas pueden

\footnotetext{
49 Recuérdense las palabras de Aristóteles sobre la rigurosidad de las demostraciones en Ética a Nicómaco $1094 \mathrm{~b}$.

50 Callahan (2019).
} 
pero no tienen que incluir referencia a las fuentes de las afirmaciones. Más probable es que alguien diga algo como "es obvio que $p$ ” o “p, ¿cómo no?”. Incluso si explícitamente no lo dicen, lo asumen. Así, si la deliberación solo es respetuosa cuando la verdad no se usa apelativamente, hemos de concluir que toda deliberación es al menos implícitamente irrespetuosa. Se volvería explícitamente irrespetuosa cuando alguien que no comparte las creencias bisagras expresa dudas acerca de ellas. En las deliberaciones políticas de sociedades diversas esa posibilidad suele verse realizada.

Ahora bien, no es necesario desesperar de la deliberación. La solución es notar que hay una concepción alternativa del respeto, que ofrece una respuesta más satisfactoria a la pregunta por la relación entre verdad y política. A eso nos abocamos en la próxima sección.

\section{RESPETO POLÍTICO Y LEY NATURAL}

Atria cree que el respeto requiere transparentar las razones de nuestras afirmaciones, pero hemos mostrado que no hay transparencia fuera de contextos particulares. Dada la ausencia de un contexto general deliberativo, no hay transparencia absoluta. La consecuencia es la imposibilidad de erradicar el uso apelativo de la verdad, con la consiguiente pretendida falta de respeto.

Afortunadamente, hay una concepción de respeto político alternativa. La llamamos "respeto institucional". El respeto discursivo tiene una idea correcta: respetar políticamente a alguien es hacerlo parte de la comunidad política. Yerra cuando entiende esa pertenencia discursivamente. Si la democracia es un sistema de igual poder político, entonces pertenecer a ella será tener el mismo poder político que los demás. Mas eso significa tener el mismo poder de decisión, esto es, ser igualmente influyente en los mecanismos por los que el Estado establece sus cursos de acción. Esos mecanismos incluyen no solo el voto mayoritario o la participación en cargos institucionales, sino también la deliberación pública. Es decir, todos los ciudadanos deben ser capaces de participar en igualdad de condiciones en la deliberación. ¿Qué significa eso? Gruesamente, poder expresar las creencias de modo que sean igualmente visibles, tener la misma influencia en cómo la deliberación se desenvuelve, y determinar los contextos deliberativos. Sin duda alguna, Chile y el resto de las democracias realmente existentes se quedan muy atrás, por lo que la igualdad democrática sigue siendo una promesa. En ese sentido, adoptar el respeto institucional también nos lleva a sostener, con Atria, que nuestras deliberaciones son imperfectas porque no vivimos vidas plenamente políticas. La diferencia crucial radica en que para nosotros una vida plenamente política se identifica con nuestra participación en las instituciones políticas, no en la transparencia de nuestras razones. No hay nada en la idea de participación institucional igualitaria que implique algún tipo de consenso o comunión de intereses.

De modo importante, el respeto institucional es compatible con la tesis de que todo contexto deliberativo trae aparejadas sus propias necesidades metodológicas. Estas favorecerán algunas posiciones sobre otras, claro está, y por lo tanto pueden parecer inconsistentes con la igual participación. No obstante, la participación no implica que todas las posiciones tengan las mismas posibilidades de ser adoptadas, o sean igualmente plausibles. El respeto institucional es efectivamente institucional y no discursivo: es la capacidad de las personas 
de participar en las instituciones de decisión política lo que importa y no el destino de sus creencias. Con todo, se puede argumentar que si el contexto deliberativo favorece a $w$ por sobre $z$, entonces quienes proponen $z$ no tienen la misma influencia en la deliberación. Eso es verdad, mas resulta que la dispar influencia no se debe a que no puedan participar del mismo modo de los mecanismos de la deliberación. La unidad de análisis no es el contenido de la deliberación, incluyendo las posiciones favorecidas o perjudicadas, sino cómo los ciudadanos pueden influir en el modo institucional en que la deliberación tiene lugar. Es decir, si pueden influir igualitariamente en los plazos, la exposición de las posturas, los recursos disponibles a los deliberantes, etcétera; siguiendo con los términos de este artículo, se trata de los aspectos "materiales" de la deliberación.

¿Pero no significa esto que las personas estarán sometidas a la voluntad de otros? El respeto discursivo explica la no sumisión a la voluntad ajena por medio de la transparencia de las razones: $\mathrm{O}$ no se somete a la voluntad de $\mathrm{H}$ si y solo si puede compartir las razones que justifican la creencia de $\mathrm{H}$. Para la concepción alternativa, por otra parte, la no sumisión se explica por medio de la participación institucional: $\mathrm{O}$ no se somete a la voluntad de $\mathrm{H}$ si y solo si $\mathrm{O}$ participa en la misma medida que $\mathrm{H}$ del proceso deliberativo. A $\mathrm{O}$ no se le "impone" la conclusión de la deliberación, si con ello se quiere decir algo más que ella ha resultado victoriosa. No es lo mismo perder la deliberación que ser tratado como un mero destinatario de las opiniones de los demás.

Significativamente, no hay sometimiento porque al no ser discursivo el respeto institucional no entiende el resultado de los procesos democráticos como una forma de manifestación de la verdad. Una deliberación es respetuosa cuando todos participan igualmente, aunque no se hayan transparentado las razones a todos. Por lo tanto, no se asume que la posición derrotada sea falsa o que no pueda ser afirmada respetuosamente como verdadera. $\mathrm{O}$ no tiene por qué aceptar que la creencia victoriosa de $\mathrm{H}$ es verdadera, sino solo que es victoriosa. El sometimiento es al proceso, que no permite inferir la verdad desde la victoria.

El razonamiento precedente puede parecer una distinción vacía, ya que en ambos casos $\mathrm{O}$ deberá someterse a una creencia que no comparte. Mas porque en el respeto discursivo lo que importa es transparentar razones $\mathrm{O}$ se somete a la fuerza del mejor argumento $^{51}$. Pero si el argumento más fuerte, según $\mathrm{O}$ lo ve, no favorece la posición de $\mathrm{H}$, entonces someterse a ella es simplemente someterse a la voluntad de $\mathrm{H}$. En el respeto institucional hay una mediación entre $\mathrm{O}$ y $\mathrm{H}$ : el procedimiento mismo. $\mathrm{O}$ se somete al procedimiento porque es parte de él, en igualdad de condiciones. Luego, es irrelevante que el argumento más fuerte no favorezca la creencia de $\mathrm{H}$, puesto que $\mathrm{O}$ no se compromete con los resultados argumentales sino con los procedimentales. O se sometería a $\mathrm{H}$ solo si $\mathrm{H}$ le impide participar en la deliberación, porque entonces la decisión se le impone desde fuera.

Lo curioso es que Atria tendría que estar de acuerdo con nosotros, al menos en parte. Recordemos que sostiene que la verdad se presenta solo en los procedimientos democráticos; esto es, que no podemos preguntarnos respetuosamente por la corrección de una conclusión sin referir a los procedimientos que la establecieron. Mas en nuestras condiciones actuales hay desacuerdos sobre qué es lo mejor para nosotros dada nuestra naturaleza,

51 Véase Habermas (1998). 
sobre el contenido de la ley natural. Como se dijo, por el momento no nos queda más que votar. El recurso a la regla de la mayoría es, nos dice, un requerimiento de la ley natural. Si hemos de tomar respetuosamente decisiones que cuenten como nuestras, pues de otro modo la vida en sociedad sería imposible, entonces "tendremos que crear un procedimiento a través del cual puedan tomarse esas decisiones" 52 . Los únicos procedimientos justos -esto es, "anticipatorios del reconocimiento radical" ${ }^{3}$ - son la deliberación democrática y el voto mayoritario. Por ello, "la ley natural exige que las normas conforme a las cuales debemos vivir no sean otras que las que han sido adoptadas por deliberación pública y decisión por mayoría" 54 . Así, la ley natural nos compromete con los procedimientos democráticos y la distinción entre el respeto discursivo defendido por Atria y el institucional colapsaría.

La diferencia estriba en la interpretación del compromiso. Para Atria este tiene una función epistémica: comprometernos con esos procedimientos es comprometernos con el único modo en que el contenido de la ley natural se hace políticamente presente. Por ende, como dijimos, la ley natural no puede funcionar como un límite anterior a los mecanismos democráticos. Esto es, no se puede emplear apelativamente. Para nosotros, tiene una función puramente normativa: es lo que el respeto entre ciudadanos iguales exige.

De nuestra interpretación se sigue otro modo de comprender el papel de la ley natural en la deliberación y regla de mayoría. Los procedimientos democráticos no tienen una dimensión anticipatoria porque, y este es quizás el mayor punto de desacuerdo con Atria, es imposible arribar al reconocimiento radical. Nunca habrá un contexto deliberativo donde todas las razones de nuestras creencias sean totalmente transparentes, porque como ya dijimos el uso apelativo de la verdad es ineludible. O mejor dicho, si es que llegase a existir un contexto en el que se lograra tal transparencia entre sus participantes eso solo mostraría lo homogénea que es esa audiencia. No sería un avance en el reconocimiento radical, sino simplemente un avance en el libro de consensos. Atria podría darse por satisfecho con eso si sus aspiraciones fuesen más modestas, a la manera del liberalismo político de Rawls. El consenso traslapado rawlsiano no pretende constituir un contexto de reconocimiento pleno, sino que asume un contexto político-social concreto. Como muchos han remarcado, el proyecto rawlsiano es una explicitación de los supuestos que ya permean la cultura política democrática liberal. Pero Atria cree algo más: que la verdad final de la moral se manifestará cuando vivamos en condiciones donde haya reconocimiento pleno.

Seamos claros. Atría podría sostener, que la situación de total reconocimiento desempeña un papel puramente regulativo. No estaría comprometido con su realización empírica, por lo que sería irrelevante que en la práctica todo contexto implique, al menos implícitamente, el uso apelativo de la verdad. Aquí se puede traer a colación el concepto de la justicia puramente procesal imperfecta. Al ser un estándar negativo lo único que nos dice es cuándo no hemos logrado el pleno reconocimiento, por lo que el que no se pueda implementar solo implica que se puede usar positivamente.

\footnotetext{
52 Atria (2016) p. 403.

53 Atria (2016) p. 404.

54 Atria (2016) p. 405.
} 
Esta respuesta falla porque el problema no es simplemente empírico. Es imposible en principio tal situación porque no se puede concebir una deliberación que parta desde la nada. Cualquier deliberación incluye forzosamente necesidades metodológicas, o no sería una práctica, es decir, algo que nosotros podamos hacer. Uno puede imaginarse una deliberación en abstracto, sin límites de tiempo, sin restricciones pragmáticas, donde todo pueda ser debatido, y toda creencia pudiera justificarse totalmente; lo importante es no dejarse llevar por la imaginación, recordando que esa situación es el modelo de una deliberación y no una versión idealizada. ¿Pero cómo el modelo podría cumplir la mentada función negativa? Es trivial que no nos hemos acercado a él con nuestras deliberaciones. De hecho, hemos hecho todo lo contrario, porque cada vez que intentamos deliberar brindamos contenido a ese modelo, alejándonos de él.

Atria afirma que "[1]a idea de la comunidad humana universal (= de la superación de lo político) es la que funda la ley natural" ${ }^{5}$. Esa comunidad es el estándar externo que la justicia puramente procedimental imperfecta emplea negativamente. Mas mientras ella se entienda discursivamente, como lo hace explícitamente Atria ${ }^{56}$, ella será imposible, si con una comunidad discursiva seguimos entendiendo el transparentar nuestras razones. Por ende, tendríamos que rechazar la posibilidad de una ley natural.

Afortunadamente, dicha posibilidad se mantiene si renunciamos a la idea de que la ley natural se revela en los procesos democráticos. Ya que el uso apelativo de la verdad es inevitable, no hay una objeción en principio al uso apelativo de la ley natural. Entonces, contra Atria, que $x$ sea conforme a la ley natural puede usarse como premisa de un argumento. Es decir, en principio no habría problemas con directamente afirmar que algo es bueno para nosotros en medio de una deliberación. Detallar en qué contextos eso no sería problemático excede este artículo, así que por el momento nos limitaremos a dos cuestiones. Primero, nótese que nada de lo que hemos dicho niega la importancia de la deliberación. En efecto, aceptamos que la ley natural requiere comprometernos con los procedimientos democráticos; luego, nos compromete con el modelo de toda deliberación. La deliberación en abstracto tiene ciertas características, insuficientes para una deliberación real pero necesarias. Lo mismo sucede con cualquier sistema de votación: se debe ajustar a un modelo. Puesto que hay incontables prácticas que podrían ocupar el lugar que nuestras prácticas de deliberación política ocupan, ¿`ómo justificamos que sean las nuestras las correctas? Obviamente responder que ellas se ajustan a la deliberación modelo solo desplaza la pregunta hacia la corrección del modelo. Cualquier respuesta tendrá que ubicarse fuera de nuestras prácticas deliberativas políticas, porque intentará fundarlas. Por lo tanto, dentro de la deliberación política dicha justificación será una de las necesidades metodológicas. Significativamente, el mismo prin-

\footnotetext{
55 ATRIa (2016) p. 397

56 Atria distingue, siguiendo a McCabe, entre "comunidad biológica" y "comunidad lingüística". La primera es una clase natural y no meramente nominal. Con McCabe, niega que esa sea la comunidad relevante, puesto que los seres humanos son seres que usan lenguaje y por lo tanto su pertenencia a la comunidad humana depende de su capacidad de comunicarse con otros humanos, y no al mero hecho biológico de pertenecer a la especie humana. Cfr. 395 y ss.
} 
cipio de respeto institucional lo postulamos como parte de la ley natural, y él informa los procedimientos democráticos sin ser una conclusión suya ${ }^{57}$.

La ley natural, luego, funcionaría como límite de la deliberación política en el sentido de que la enmarca. Naturalmente, y este es nuestro segundo punto, lo anterior no implica que los principios de la ley natural requieran "un acceso especial a la verdad o a la revelación" ${ }^{58}$. Es compatible con lo expuesto que lleguemos a ellos mediante procesos de argumentación racional, o gracias a intuiciones disponibles a todos ${ }^{59}$, etcétera. Lo único que negamos es que todo el contenido de la ley natural sea una conclusión de los procesos democráticos, y que por ello no pueda utilizarse como premisa argumental. De nuestro razonamiento se sigue que no hay un contexto deliberativo en el que pueda mostrarse la ley natural originariamente, como querría Atria. En términos más generales, no hay ningún contexto en el que la verdad se muestre originariamente, pues siempre está presupuesta. Quizás los principios de la ley natural son conclusiones de múltiples contextos, que a su vez se presuponen entre sí. Como sea, seguiría siendo el caso que en cada uno de ellos se emplea la verdad apelativamente.

Volvamos a la pregunta inicial: ‘hay algo inapropiado en referir a la verdad en la deliberación política democrática? La teoría de Atria es un intento notable de respuesta (parcialmente) afirmativa. Si los argumentos de este artículo son correctos, su teoría es errónea y tenemos razones para responder que no solo no es inapropiado sino que es inevitable.

\section{BIBLIOGRAFÍA CITADA}

Arancibia Collao, Fernando (2018): "Natural Law Moral Epistemology: Naturalist, Intuitionist or both?", Rechtstheorie, vol. 49, No 2: pp. 131-153.

Arendt, Hannah (1961): "Truth and Politics", en Arendt, Hannah (ed.) Between Past and Future (New York: Viking Press) pp. 227-64.

Atria Lemaitre, Fernando (2014): Derechos Sociales y Educación: Un Nuevo Paradigma de lo Público (Santiago, Lom ediciones).

Atria Lemaitre, Fernando (2016): La Forma del Derecho (Madrid, Marcial Pons).

Atria Lemaitre, Fernando (2018): "La Razón Bruta”. Disponible en: https://media.elmostrador.cl/2018/05/Atria_Razon_bruta.pdf. Fecha de consulta: 23 de mayo de 2020.

Atria Lemaitre, Fernando y otros (2013): El Otro Modelo: Del orden Neoliberal al Régimen de lo Público (Santiago, Debate).

Besch, Thomas M. (2014): "On discursive respect", Social Theory and Practice, vol. 40, No 2: pp. 207-231.

Callahan, Laura Frances (2019): “Epistemic Existentialism”, Episteme, Firts View Articles pp. 1-16.

Cohen, Gerald Allan (2009): Why Not Socialism? (Princeton, Princeton University Press).

\footnotetext{
57 Estlund (2012) argumenta que el liberalismo político tiene que aceptar que el principio de legitimidad liberal, que se encuentra a la base del proyecto rawlsiano, es verdadero y no meramente razonable. Dados los paralelos del liberalismo político con la posición atriana resulta sugerente la argumentación de Estlund.

58 Atria (2016) p. 398.

59 Véase Arancibia (2018).
} 
DaHL, Robert (1989): Democracy and Its Critics (New Haven, Yale University Press, First Edition).

Darwall, Stephen L. (1977): “Two kinds of respect", Ethics, vol. 88, No 1: pp. 36-49.

Estlund, David (2012): "The Truth in Political Liberalism”, en Norris, Andrew y Elkins, Jeremy (ed.) Truth and Democratic Politics (Philadelphia, University of Pennsylvania Press).

FinNIS, John (1983): Fundamentals of Ethics (Georgetown, Georgetown University Press).

FORST, Rainer (2011): The Right to Justification: Elements of a constructivist theory of justice (trad. por J. Flynn, New York, Columbia University Press).

Gaus, Gerald F. (2011): The Order of Public Reason: A Theory of Freedom and Morality in a Diverse and Bounded World (Cambridge, Cambridge University Press).

Gutmann, Amy y Thompson, Dennis (1996): Democracy and Disagreement (Cambridge, MA, Belknap Press of Harvard University Press).

Habermas, Jürgen (1998): Between Facts and Norms: Contributions to a Discourse Theory of Law and Democracy (trad. W. Rehg, Cambridge, Mass., The MIT Press).

Larmore, Charles (1987): Patterns of Moral Complexity (Cambridge, Cambridge University Press).

MacIntyre, Alasdair (1987): Tras la Virtud (Barcelona, Crítica).

Nagel, Thomas (1987): "Moral conflict and political legitimacy", Philosophy \& Public Affairs, vol. 16, № 3: pp. 215-240.

NozIck, Robert (1974): Anarchy, State and Utopia (Oxford, Basil Blackwell).

Pritchard, Duncan (2018): "Unnatural doubts", en Bruno, G. Anthony y Rutherford, Abby (ed.) Skeptical Solutions: Provocations of Philosophy (Oxford, Oxford University Press), pp. 223-247.

RAwLS, John (1999): A Theory of Justice (Cambridge, MA, Belknap Press of Harvard University Press).

Rawls, John (2005): Political Liberalism: Expanded Edition (New York, Columbia University Press).

RorTy, Richard (1983): "Postmodernist Bourgeois Liberalism", The Journal of Philosophy, vol. 80, No 10: pp. 583-89.

SCanlon, Thomas M. (1996): "The Difficulty of Tolerance”, en Heyd, David (ed.) Toleration: An Elusive Virtue (Cambridge, Cambridge University Press), pp. 226-39.

SCAnlon, Thomas M. (1998): What We Owe to Each Other (Cambridge, MA, Belknap Press of Harvard University Press).

Williams, Michael (2007): "Why (Wittgensteinian) contextualism is not relativism", Episteme, vol. 4, No 1: pp. 93-114.

Wittgenstein, Ludwig (1969): En Anscombe, Gertrude Elizabeth Margaret y Von Wright, George Henrik (ed.) On Certainty (trad. Denis Paul y Gertrude Elizabeth Margaret Anscombe, Oxford, Basil Blackwell). 